\title{
Implementasi Algoritma K-Medoids untuk Pengelompokkan Sebaran Mahasiswa Baru
}

\author{
Eka Irawan', Sandy Putra Siregar', Irfan Sudahri Damanik ${ }^{3}$, Ilham Syaputra Saragih ${ }^{4}$ \\ 1,2,3,4 Program Studi Sistem Informasi, STIKOM Tunas Bangsa \\ Jl. Jend. Sudirman Blok A no 1,2 dan 3 Pematangsiantar \\ eka.irawan@amiktunasbangsa.ac.id
}

\begin{abstract}
The existence of new students at a tertiary institution is a routine activity every year in a tertiary institution and can also see the sustainability of the tertiary institution. The variety of regional origin of new students makes the party from the university want to see the distribution of new students based on the origin of the school and its place of residence. STIKOM Tunas Bangsa is one of the tertiary institutions in Pematangsiantar. It aims to promote the university. K-Medoids is able to group data on the distribution of new students in STIKOM Tunas Bangsa Pematangsiantar. The clusters produced in this study are of three clusters. The validity used in this study is the validity of Silhoutte Coefficient. The validity value generated in the K-Medoids algorithm produces a validity value of -116.47 by assuming that if the non-medoids value produced $S<0$ then the cluster process is stopped.
\end{abstract}

Keywords: Distribution, Clustering, Data Mining, KMedoids, Validation

\begin{abstract}
Abstrak
Keberdaan mahasiswa baru pada suatu perguruan tinggi merupakan kegiatan rutin setiap tahunya dalam sebuah pergutuan tinggi dan dapat juga melihat keberlangsungan suatu perguruan tinggi tersebut. Beragamnya asal wilayah dari mahasiswa baru membuat pihak dari perguruan tinggi ingin melihat persebaran mahasiswa baru berdasarkan asal sekolah dan tempat tinggalnya. STIKOM Tunas Bangsa merupakan salah satu perguruan tinggi yang ada di pematangsiantar Bertujuan untuk melakukan promosi dari perguruan tinggi tersebut. K-Medoids mampu melakukan pengelompokan pada data sebaran mahasiswa baru yang ada pada STIKOM Tunas Bangsa Pematangsiantar. Klaster yang dihasilkan pada penelitian ini adalah berjumlah tiga klaster. Validitas yang digunakan pada penelitian ini adalah validitas Silhoutte Coefficient. Adapun nilai validitas yang dihasilkan pada algoritma K-Medoids menghasilkan nilai validitas sebesar -116,47 dengan mengasumsikan bahwa jika nilai non medoids yang dihasilkan $S<0$ maka proses cluster dihentikan.
\end{abstract}

Kata Kunci: Sebaran, Clustering, Data Mining, KMedoids, Validasi

\section{PENDAHULUAN}

Data mining dapat diterapkan untuk menggali nilai tambah dari suatu kumpulan data berupa pengetahuan yang selama ini tidak diketahui secara manual. Terdapat beberapa teknik yang digunakan dalam data mining, salah satu teknik data mining adalah clustering [1]. Terdapat dua jenis metode clustering yang digunakan dalam pengelompokkan data, yaitu hierarchical clustering dan nonhierarchical clustering.

Algoritma clustering salah satunya adalah $K$-Medoids yang termasuk salah satu metode pengelompokkan di dalam data mining. Algoritma ini menggunakan objek pada kumpulan objek untuk mewakili sebuah cluster. Metode K-Medoids cukup efisien untuk dataset yang kecil. Kelebihan dari metode $K$-Medoids mampu mengatasi kelemahan dari metode K-Means yang sensitive terhadap outlier dan hasil proses clustering tidak bergantung pada urutan masuk dataset [2] Dalam hal ini penulis menggunakan algoritma K-Medoids dengan tools Rapidminer dalam 
mengelompokkan kemiskinan menurut provinsi. Diharapkan dengan adanya penelitian ini dapat membantu pemerintah dalam meningkatkan sumber daya ekonomi penduduk, sehingga dapat membantu penduduk yang kurang mampu.

Berdasarkan berlimpahnya data mahasiswa, informasi yang tersembunyi dapat diketahui dengan cara melakukan pengolahan terhadap data tersebut sehingga berguna bagi pihak universitas [3]. Pengolahan data mahasiswa perlu dilakukan untuk mengetahui informasi penting berupa pengetahuan baru (knowledge discovery), misalnya informasi mengenai pengelompokan data mahasiswa berpotensi berdasarkan kota asal mahasiswa [3]. Suatu perguruan tinggi menyimpan data akademik, administrasi, biodata mahasiswa dan lain-lain. Data tersebut akan sangat bermakna jika digali dengan tepat sehingga dapat diketahui pola atau pengetahuan untuk mengambil keputusan [4]. Selain pengambilan data, studi literatur satu cara untuk menemukan atau melengkapi penelitian yang sedang dilakukan sebagai referensi untuk melakukan penelitian menjadi lebih lengkap[5]. Pengetahuan baru tersebut dapat membantu pihak sekolah tinggi dalam menentukan strategi promosi terhadap calon mahasiswa baru dengan tepat sasaran. Berdasarkan latar belakang masalah di atas, penulis mengambil judul "Implementasi Algoritma K-Medoids untuk Pengelompokkan Asal Sekolah Sebaran Mahasiswa Baru". Diharapkan penelitian ini dapat mengetahui dimana asal sekolah terbanyak dan tersedikit berdasarkan cluster tinggi dan rendah untuk melakukan promosi.

\section{METODOLOGI PENELITIAN}

Dalam penelitian ini menggunakan metode datamining dengan $\mathrm{K}$ - medoid antara lain: a) Tahap pengumpulan data, b) Analisis kebutuhan, c) Pengolahan Data, d) Tahap clustering dan e) Tahap Analisis.

\subsection{Tahap Pengumpulan Data}

Data yang dibutuhkan dalam penelitian ini adalah data asal sekolah mahasiswa yang terdapat di STIKOM Tunas Bangsa yabf di peroleh dari BAK STIKOM Tunas Bangsa. Data yang digunakan berisi NIM, Nama Mahsiswa, Alamat Dan Asal Sekolah. Data yang digunakan dari tahun 2017 sampai dengan 2019.

\subsection{Analisi kebutuhan}

Analisa kebutuhan dilakukan dengan menentukan kebutuhan apa saja yang dibutuhkan dalam pengimplementasian metode K-Medoids clustering untuk pengelompokkan data persebaran mahasiswa STIKOM Tunas Bangsa berdasarkan asal Sekolah.

\subsection{Tahap Pengelolahan Data}

Data diolah menjadi 2 cluster yaitu cluster tingkat fasilitas tertinggi (C1) dan cluster tingkat fasilitas terendah (C2) sehingga dapat diperoleh perhitunagan nilai yg akan di peroses pada tahap selanjutnya, data setiap wilayah yang memiliki fasilitas perguruan tinggi akan dijumlah setiap aspeknya sehingga pada langkah ini sudah diperoleh data perhitungan nilai yang akan diproses pada prosedur clustering. Proses pengolahan menggunakan bantuan aplikasi RapidMiner. 


\subsection{Tahap Clustering}

Clustering merupakan klasifikasi tanpa pengawasan dan merupakan proses partisi sekumpulan objek data dari satu set menjadi beberapa kelas. Hal ini dapat dilakukan dengan menerapkan berbagai persamaan dan langkah-langkah mengenai jarak algoritma.

\subsection{Tahap Analisis}

Pada tahapan ini dilakukan analisis persebaran mahasiswa berdasarkan asal sekolah kemudian akan di lakukan analisis berdasarkan sekolah asal, mana sekolah yang banyak menyumbangkan siswanya dengan sekolah yang sedikit menyumbangkan siswanya. Tujuannya agar dapat melakukan marketing ke beberapa sekolah yang memiliki peluang masuk STIKOM Tunas Bangsa.

\section{HASIL DAN PEMBAHASAN}

Pada tahap ini pengolahan data kemiskinan menurut provinsi di Indonesia menggunakan algoritna k-medoids dengan tool Rapidminer. Rapidminer adalah software pilihan untuk melakukan ekstraksi data dengan metode-metode data mining. Berikut adalah data kemiskinan di indonesia diambil dari Badan Pusat Statistika (BPS) pada gambar 1.

Berikut Tahapan dalam proses perhitungan manual menggunakan algoritma k-medoids.

a. Memilih secara acak centroid awal, Berikut penentuannya terdapat pada tabel 1 .

Tabel 1. Centroid Awal Medoids

\begin{tabular}{|c|c|c|c|c|}
\hline Nama & Keterangan & $\mathbf{X}$ & $\mathbf{Y}$ & $\mathbf{Z}$ \\
\hline C1 & Data ke-3 dengan sebagai pusat cluster ke-1 & 2 & 2 & 2 \\
\hline C2 & Data ke-4 dengan sebagai pusat cluster ke-1 & 1 & 1 & 1 \\
\hline C3 & Data ke-5 dengan sebagai pusat cluster ke-1 & 2 & 3 & 1 \\
\hline
\end{tabular}

b. Penempatan Objek-objek non medoids ke dalam cluster paling dekat dengan medoids berdasarkan jarak Euclidean. Contoh perhitungan jarak terdekat pada data ke-1 :

$$
\begin{aligned}
& A l-\text { Wasliyah }_{(C 1)}=\sqrt{(1-2)^{2}+(1-2)^{2}+(2-2)^{2}=1,41} \\
& A l-\text { Washliyah }_{(C 2)}=\sqrt{(1-1)^{2}+(1-1)^{2}+(2-1)^{2}=1,00} \\
& A l-\text { Washliyah }_{(C 3)}=\sqrt{(1-2)^{2}+(1-3)^{2}+(2-1)^{2}=2,45}
\end{aligned}
$$

Perhitungan jarak data ke-2 sampai data ke-73 ke setiap medoids, sehingga hasil dari data keseluruhannya dapat diperoleh terdapat pada table 2 berikut.

Tabel 2. Hasil Perhitungan Jarak Ke Setiap Medoids

\begin{tabular}{|l|c|c|c|c|c|}
\hline \multicolumn{1}{|c|}{ Data Ke - i } & C1 & C2 & C3 & Terdekat & Klaster \\
\hline AL WASHLIYAH KM.6 MEDAN & 1,41 & 1,00 & 2,45 & 1,00 & 2 \\
\hline $\begin{array}{l}\text { AMIK TUNAS BANGSA } \\
\text { PEMATANGSIANTAR }\end{array}$ & 23,69 & 25,42 & 23,77 & 23,69 & 1 \\
\hline $\begin{array}{l}\text { MA AL WASHLIYAH } \\
\text { SERBELAWAN }\end{array}$ & 0,00 & 1,73 & 1,41 & 0,00 & 1 \\
\hline MA IBNU SINA & 1,73 & 0,00 & 2,24 & 0,00 & 2 \\
\hline
\end{tabular}




\begin{tabular}{|c|c|c|c|c|c|}
\hline Data Ke - i & C1 & C2 & C3 & Terdekat & Klaster \\
\hline MA SWASTA IKHLASIYAH GUPPI & 1,41 & 2,24 & 0,00 & 0,00 & 3 \\
\hline$\ldots \ldots \ldots \ldots$ & \multirow{2}{*}{\multicolumn{5}{|c|}{$\ldots+\cdots \cdots \cdots \cdots \cdots \cdots \cdots$}} \\
\hline ............. & & & & & ……...................... \\
\hline $\begin{array}{l}\text { SMK SWASTA TAMAN SISWA } \\
\text { PEMATANG SIANTAR }\end{array}$ & 8,12 & 9,85 & 8,12 & 8,12 & 3 \\
\hline $\begin{array}{l}\text { SMK SWASTA TELADAN } \\
\text { PEMATANGSIANTAR }\end{array}$ & 22,91 & 24,54 & 20,81 & 20,81 & 3 \\
\hline $\begin{array}{l}\text { SMK SWASTA TELADAN TANAH } \\
\text { JAWA }\end{array}$ & 3,32 & 4,00 & 3,61 & 3,32 & 1 \\
\hline $\begin{array}{l}\text { SMK SWASTA TRISAKTI KOTA } \\
\text { PEMATANGSIANTAR }\end{array}$ & 2,24 & 2,45 & 3,32 & 2,24 & 1 \\
\hline $\begin{array}{l}\text { SMK SWASTA TUNAS JAYA } \\
\text { TANAH JAWA }\end{array}$ & 2,00 & 1,73 & 2,45 & 1,73 & 2 \\
\hline $\begin{array}{l}\text { SMK SWASTA YP HKBP KOTA } \\
\text { PEMATANGSIANTAR }\end{array}$ & 2,45 & 2,24 & 3,16 & 2,24 & 2 \\
\hline Jumlah & 420,88 & 458,58 & 432,58 & & \\
\hline Total Cost & \multicolumn{3}{|c|}{383,97} & & \\
\hline
\end{tabular}

c. Mengasumsikan objek telah ditentukan sebagai non medoids berikut :

Tabel 3. Non Medoids

\begin{tabular}{|c|c|c|c|c|}
\hline Nama & Keterangan & X & Y & Z \\
\hline C1 & Data ke-68 dengan sebagai pusat cluster ke-0 & 7 & 7 & 6 \\
\hline C2 & Data ke-73 dengan sebagai pusat cluster ke-1 & 3 & 0 & 1 \\
\hline C3 & Data ke-69 dengan sebagai pusat cluster ke-2 & 12 & 21 & 10 \\
\hline
\end{tabular}

d. Penempatan Objek-objek non medoids ke dalam cluster paling dekat dengan medoids berdasarkan jarak Euclidean. Contoh perhitungan jarak terdekat pada data ke-1 :

$$
\begin{aligned}
& A l-\text { Washliyah }_{(C 1)}=\sqrt{(1-7)^{2}+(1-7)^{2}+(2-6)^{2}}=9,38 \\
& A l-\text { Washliyah }_{(C 2)}=\sqrt{(1-3)^{2}+(1-0)^{2}+(2-1)^{2}}=2,45 \\
& A l-\text { Washliyah }_{(C 3)}=\sqrt{(1-12)^{2}+(1-21)^{2}+(2-10)^{2}}=24,19
\end{aligned}
$$

\begin{tabular}{|c|c|c|c|c|c|}
\hline Asal Sekolah & C1 & C2 & C3 & Terdekat & Klaster \\
\hline AL WASHLIYAH KM.6 MEDAN & 9,38 & 2,45 & 24,19 & 2,45 & 2 \\
\hline $\begin{array}{l}\text { AMIK Tunas Bangsa } \\
\text { Pematangsiantar }\end{array}$ & 15,65 & 24,88 & 9,38 & 9,38 & 3 \\
\hline MA AL WASHLIYAH SERBELAWAN & 8,12 & 2,45 & 22,91 & 2,45 & 2 \\
\hline MA IBNU SINA & 9,85 & 2,24 & 24,54 & 2,24 & 2 \\
\hline MA SWASTA IKHLASIYAH GUPPI & 8,12 & 3,16 & 22,47 & 3,16 & 2 \\
\hline .............. & \multicolumn{5}{|c|}{ 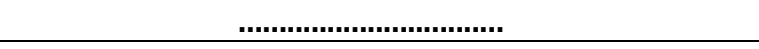 } \\
\hline .............. & \multicolumn{5}{|c|}{........................................... } \\
\hline $\begin{array}{l}\text { SMK SWASTA TAMAN SISWA } \\
\text { PEMATANG SIANTAR }\end{array}$ & 0,00 & 9,49 & 15,39 & 0,00 & 1 \\
\hline $\begin{array}{l}\text { SMK Swasta Teladan } \\
\text { Pematangsiantar }\end{array}$ & 15,39 & 24,56 & 0,00 & 0,00 & 3 \\
\hline
\end{tabular}

e. Sehingga hasil yang diperoleh seperti tabel 4 berikut.

Tabel 4. Hasil Perhitungan Jarak Ke Setiap Medoids 


\begin{tabular}{|c|c|c|c|c|c|}
\hline Asal Sekolah & C1 & $\mathrm{C} 2$ & C3 & Terdekat & Klaster \\
\hline $\begin{array}{l}\text { SMK SWASTA TELADAN TANAH } \\
\text { JAWA }\end{array}$ & 8,06 & 2,24 & 23,02 & 2,24 & 2 \\
\hline $\begin{array}{l}\text { SMK SWASTA TRISAKTI KOTA } \\
\text { PEMATANGSIANTAR }\end{array}$ & 9,11 & 2,24 & 24,29 & 2,24 & 2 \\
\hline $\begin{array}{l}\text { SMK SWASTA TUNAS JAYA TANAH } \\
\text { JAWA }\end{array}$ & 9,49 & 3,74 & 23,85 & 3,74 & 2 \\
\hline $\begin{array}{l}\text { SMK Swasta YP HKBP Kota } \\
\text { Pematangsiantar }\end{array}$ & 9,49 & 0,00 & 24,56 & 0,00 & 2 \\
\hline Jumlah & 645,21 & 483,22 & 1488,38 & & \\
\hline Total Cost & \multicolumn{3}{|c|}{271,50} & & \\
\hline
\end{tabular}

f. Hitung total simpangan $(S)$ dengan menghitung total distance baru - total distance lama. Jika $S<0$ maka tukar objek dengan data cluster untuk membentuk sekumpulan $k$ objek baru sebagai medoids.

$S=$ total distance baru - total distance lama

$S=271,50-387,97=-116,47$

g. Jika nilai $\mathrm{S}<0$ maka proses pengklasteran dihentikan. Sehingga menghasilkan Cluster Dapat dilihat pada tabel berikut.

Tabel 5. Hasil Pengklasteran dengan K-Medoids

\begin{tabular}{|c|c|c|c|c|c|}
\hline Asal Sekolah & C1 & $\mathrm{C} 2$ & C3 & Terdekat & Klaster \\
\hline AL WASHLIYAH KM.6 MEDAN & 9,38 & 2,45 & 24,19 & 2,45 & 2 \\
\hline AMIK Tunas Bangsa Pematangsiantar & 15,65 & 24,88 & 9,38 & 9,38 & 3 \\
\hline MA AL WASHLIYAH SERBELAWAN & 8,12 & 2,45 & 22,91 & 2,45 & 2 \\
\hline MA IBNU SINA & 9,85 & 2,24 & 24,54 & 2,24 & 2 \\
\hline MA SWASTA IKHLASIYAH GUPPI & 8,12 & 3,16 & 22,47 & 3,16 & 2 \\
\hline (............ & \multicolumn{5}{|c|}{ 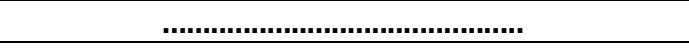 } \\
\hline (............ & \multicolumn{5}{|c|}{ t................................................... } \\
\hline $\begin{array}{l}\text { SMK SWASTA TAMAN SISWA } \\
\text { PEMATANG SIANTAR }\end{array}$ & 0,00 & 9,49 & 15,39 & 0,00 & 1 \\
\hline SMK Swasta Teladan Pematangsiantar & 15,39 & 24,56 & 0,00 & 0,00 & 3 \\
\hline SMK SWASTA TELADAN TANAH JAWA & 8,06 & 2,24 & 23,02 & 2,24 & 2 \\
\hline $\begin{array}{l}\text { SMK SWASTA TRISAKTI KOTA } \\
\text { PEMATANGSIANTAR }\end{array}$ & 9,11 & 2,24 & 24,29 & 2,24 & 2 \\
\hline $\begin{array}{l}\text { SMK SWASTA TUNAS JAYA TANAH } \\
\text { JAWA }\end{array}$ & 9,49 & 3,74 & 23,85 & 3,74 & 2 \\
\hline $\begin{array}{l}\text { SMK Swasta YP HKBP Kota } \\
\text { Pematangsiantar }\end{array}$ & 9,49 & 0,00 & 24,56 & 0,00 & 2 \\
\hline
\end{tabular}

Pada tabel diatas dapat dianalisa kesimpulan yang dimiliki adalah bahwa data yang digunakan valid, dengan hasil akhir perhitungan di Rapidminer 5.3 dengan perhitungan excel menampilkan hasil akhir yang sama. Berikut tampilan cluster model yang berada di Rapidminer. 


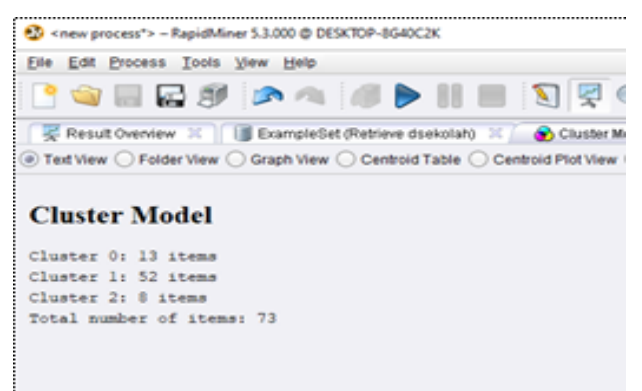

Gambar 1. Cluster Model Pada Rapidminer

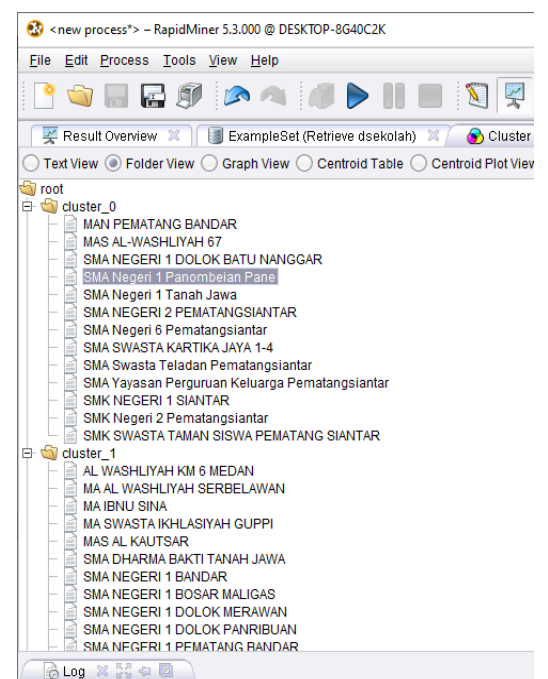

Gambar 2. Cluster Folder View Rapidminer 5.3

Persebaran cluster pada software rapidminer 5.3 dapat dilihat pada gambar 3 . Sebagai berikut:

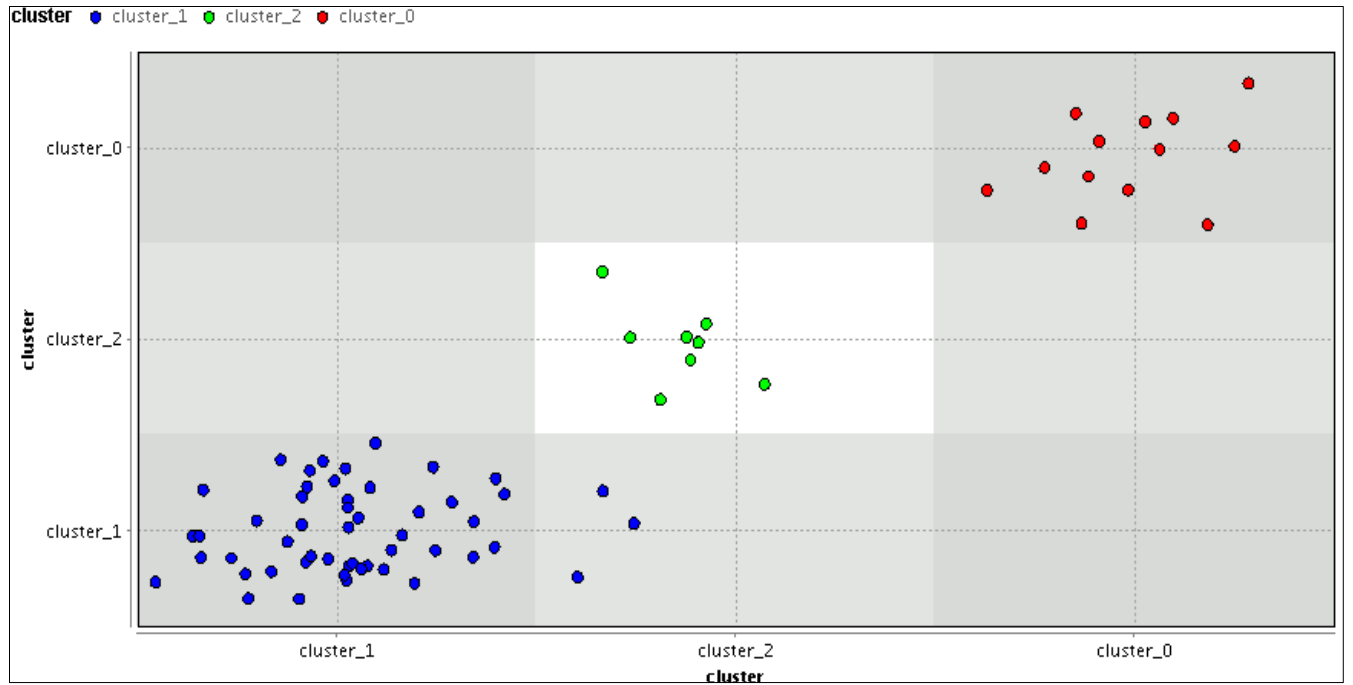

Gambar 3. Persebaran cluster Mahasiswa Baru

\section{SIMPULAN}

Pada hasil analisis dan pembahasan persebaran mahasiswa baru diatas menggunakan 3 cluster yakni klaster tinggi (0), klaster sedang (2), dan klaster rendah (1). Berdasarkan perhirungan $k$-medoids didapatkan cluster tinggi sebanyak 13 items, Cluster Sedang sebanyak 8 items dan cluster rendah sebanyak 52 items. Pada Proses clustering menggunakan K-Medoids dengan metode silhouette coefficient menghasilkan nilai validitas sebesar $-116,47$ dengan mengasumsikan bahwa jika nilai non medoids yang dihasilkan $\mathrm{S}<0$ maka proses cluster dihentikan. Pengelompokan menggunakan algoritma $\mathrm{K}$-Medoids pada kasus sebaran mahasiswa baru diperoleh jumlah cluster model yang sama di aplikasi Rapidminer 5.3 dengan perhitungan manual sehingga dihasilkan data yang valid. 


\section{DAFTAR PUSTAKA}

[1] Sudirman, A. P. Windarto, and A. Wanto, "Data mining tools | rapidminer: K-means methodon clustering of rice crops by province as efforts to stabilize food crops in Indonesia," IOP Conf. Ser. Mater. Sci. Eng., vol. 420, no. 1, 2018, doi: 10.1088/1757899X/420/1/012089.

[2] Abdillah, G., Putra, F. A., \& Renaldi, F. (2016). Penerapan Data Mining Pemakaian Air Pelanggan Untuk Menentukan Klasifikasi Potensi Pemakaian Air Pelanggan Baru Di Pdam Tirta Raharja Menggunakan Algoritma K-Means. Seminar Nasional Teknologi Informasi Dan Komunikasi, 2016(Data Mining), 18-19.

[3] Johan Oscar Ong, "Implementasi Algoritma K-Means Clustering Untuk Menentukan Strategi Marketing President University," Jurnal Ilmiah Teknik Industri, vol. 12, no. 1, pp. 10-13, Juni 2013

[4] Ogor. (2007). Student Academic Performance Monitoring and Evaluation Using Data Mining Techniques.

[5] Sandy Putra Siregar, and A. Wanto. "Analysis Accuracy of Artificial Neural Network Using Backpropagation Algorithm In Predicting Process (Forecasting)" International Journal Of Information System \& Technology Vol. 1, No. 1, (2017) , pp. 34-42 